Abdominal aortic aneurysm with spontaneous aorto-left renal vein fistula is a rare but well-described clinical entity, usually accompanied by abdominal pain, hematuria, and a nonfunctioning left kidney ${ }^{(1)}$. In male patients, left varicocele may result from venous overload in the pampiniform plexus via the left gonadal vein $^{(2)}$. A review of the literature revealed only approximately 30 other reported cases ${ }^{(3-6)}$. Aorto-left renal vein fistula is often seen in patients with a retroaortic left renal vein, an anatomical variant present in $1.0 \%$ to $2.4 \%$ of the population ${ }^{(7)}$. It has been postulated that the vein is compressed between the pulsating aneurysm and the vertebral bodies, leading to erosion of the vessel wall and fistula formation. Open repair is the recognized method of treating rupture of an abdominal aortic aneurysm into a retroaortic left renal vein. Endovascular treatment is an attractive modality because it is minimally invasive, given its capacity for rapid percutaneous arterial access and graft deployment, as well as, if necessary, balloon occlusion for vascular control, thus minimizing blood loss in comparison with open surgery ${ }^{(8)}$. To our knowledge, this is the sixth reported case in which endovascular repair of this type of fistula has been attempted.

\section{REFERENCES}

1. Mansour MA, Rutherford RB, Metcalf RK, et al. Spontaneous aorta-left renal vein fistula: the "abdominal pain, hematuria, silent left kidney" syndrome. Surgery. 1991;109:101-6.
2. Meyerson SL, Haider SA, Gupta N, et al. Abdominal aortic aneurysm with aorta-left renal vein fistula with left varicocele. J Vasc Surg. 2000;31:802-5.

3. Kamali D, Dobson G, Stannard A, et al. Complete endovascular management of a spontaneous aorto-left renal vein fistula caused by ruptured abdominal aortic aneurysm under local anaesthetic: a case report. Eur J Vasc Endovasc Surg. 2014;47:455-6.

4. Yagdi T, Atay Y, Engin C, et al. Aorta-left renal vein fistula in a woman. Tex Heart Inst J. 2004;31:435-8.

5. Faucherre M, Haftgoli-Bakhtiari N, Menth M, et al. Aorto-venous fistula between an abdominal aortic aneurysm and an aberrant renal vein: a case report. J Med Case Rep. 2010;4:255.

6. Dragas M, Davidovic L, Pejkic S, et al. Aorto-left renal vein fistula is a rare complication of abdominal aortic aneurysm with unique clinical presentation. J Vasc Surg. 2010;52:1658-61.

7. Yesildag A, Adanir E, Köroglu M, et al. Incidence of left renal vein anomalies in routine abdominal CT scans. Tani Girisim Radyol. 2004;10:140-3.

8. Ferrari M, Berchiolli R, Sardella SG, et al. Endovascular repair of an aorto-left renal vein fistula due to a ruptured abdominal aortic aneurysm after EVAR. J Endovasc Ther. 2005;12:512-5.

Leonor Garbin Savarese ${ }^{1}$, Henrique Simão Trad $^{2}$, Edwaldo Edner Joviliano ${ }^{1}$, Valdair Francisco Muglia ${ }^{1}$, Jorge Elias Junior ${ }^{1}$

1. Faculdade de Medicina de Ribeirão Preto da Universidade de São Paulo (FMRP-USP), Ribeirão Preto, SP, Brazil. 2. CEDIRP - Central de Diagnóstico Ribeirão Preto, Ribeirão Preto, SP, Brazil. Mailing address: Dra. Leonor Garbin Savarese. FMRP-USP. Avenida Bandeirantes, 3900, Monte Alegre. Ribeirão Preto, SP, Brazil, 14049-900. E-mail: leonorsavarese@hotmail.com.

http://dx.doi.org/10.1590/0100-3984.2016.0070

\title{
Pulmonary involvement in Gaucher disease
}

\section{Dear Editor,}

A 33-month-old female patient was referred to the radiology department for evaluation of a two-week history of tachycardia syndrome, presenting without fever or general impairment. She was the daughter of consanguineous parents (first cousins) and had been diagnosed at 7 months of age with Gaucher disease (GD) type 2, on the basis of the evaluation of enzymatic activity. An initial investigation with conventional chest X-ray (Figure 1) revealed a bilateral reticulonodular interstitial pattern. Multidetector computed tomography (MDCT) revealed marked, diffuse thickening of the interlobular and intralobular septa, interspersed with areas of lesser involvement, accompanied by ground-glass opacity of the lung parenchyma, characterizing the crazy-paving pattern (Figure 2).

GD has an autosomal recessive pattern of inheritance and corresponds to glucocerebrosidase deficiency, resulting in the accumulation of glucocerebrosides in macrophages of the reticuloendothelial system; macrophages that have thus been altered are referred to as Gaucher cells ${ }^{(1-3)}$. That accumulation mainly causes hyperplasia of the liver, spleen, and lymph nodes, hepatosplenomegaly being the principal characteristic of the disease. The lungs, skin, eyes, kidneys, and heart are rarely involved ${ }^{(1-6)}$. GD is the most prevalent lysosomal storage disease and is traditionally classified into three major phenotypes: type 1 (the chronic, non-neuropathic, adult type), which accounts for $99 \%$ of all cases and is characterized by a clinical profile with little clinical evidence; type II (the acute, neuropathic, infantile type), which usually results in death before the age of two years due to pneumonia and anoxia; and type III (the subacute, neuropathic, juvenile type), which has a heterogeneous course. Other less prevalent types are the perinatal-lethal and cardiovascular forms ${ }^{(2-6)}$.

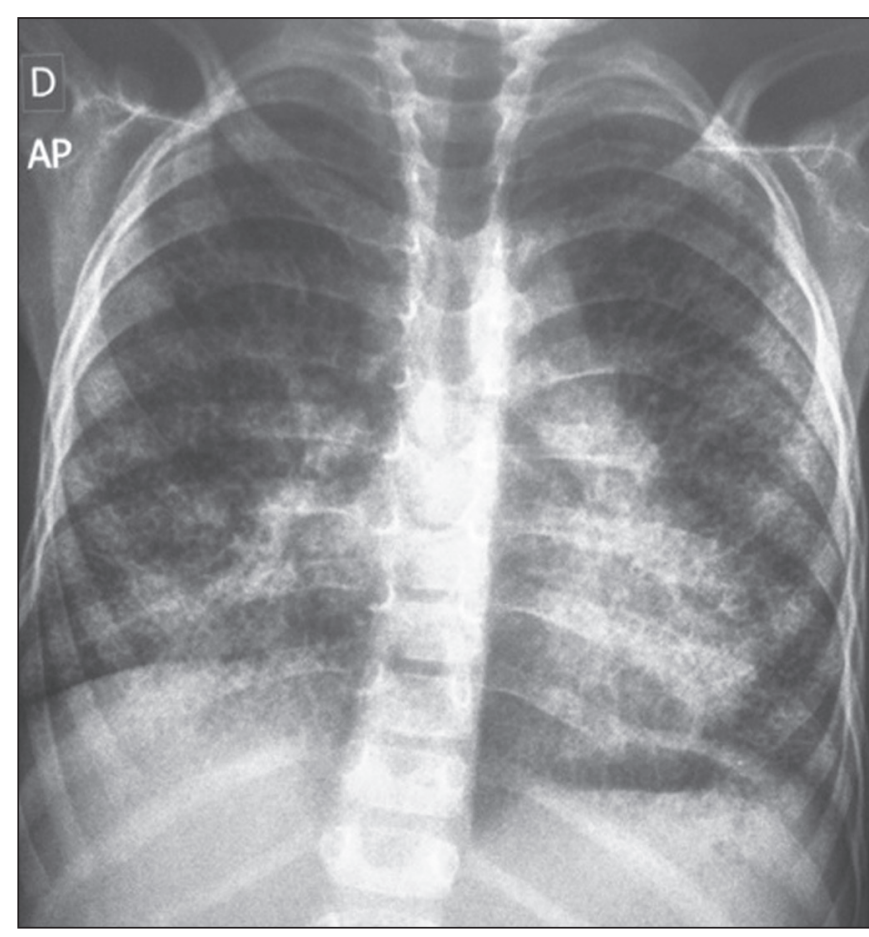

Figure 1. Anteroposterior chest X-ray showing a bilateral reticulonodular interstitial pattern that is more pronounced in the lower lobes.

Although pulmonary involvement is considered rare in GD, it has been frequently identified. However, there have been no epidemiological studies of the issue. In the literature, there is a lack of standardization of the radiological presentations of GD, due to the multifactorial involvement with multiple patterns of tissue infiltration by Gaucher cells ${ }^{(4,6,7)}$.

The imaging characteristics of GD correspond to several pathophysiological mechanisms. In addition to thickening of the 

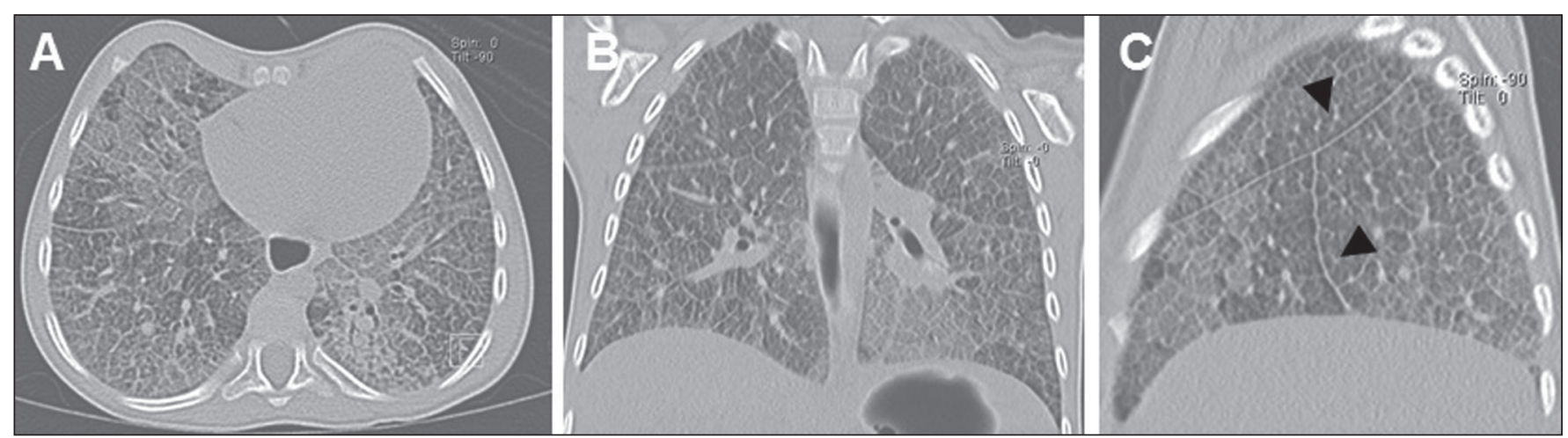

Figure 2. Axial (A), coronal (B), and sagittal (C) MDCT scans of the right lung showing diffuse, marked thickening of the interlobular and intralobular septa, accompanied by ground-glass opacity of the lung parenchyma, characteristic of the crazy-paving pattern. Note also the irregularity with the pleural surface and the thickening of the fissures (arrowheads).

interlobular and intralobular septa, patients with GD can present with alveolar opacities, capillary plugging by Gaucher cells, and interstitial opacities, with a predominance of lymphatic distribution, as well as respiratory infections ${ }^{(4-8)}$. Other alterations described include pulmonary fibrosis, a miliary pattern and involvement of the hilar or mediastinal lymph nodes, as well as a reduction in lung volume as a consequence of hepatosplenomegaly. Radiographic examinations can reveal an interstitial pattern and can show any changes in bone structures ${ }^{(3-7)}$.

The diffuse pulmonary involvement seen in patients with GD indicates that it is a systemic disease. MDCT is an important tool for the initial evaluation and follow-up of these patients, and lung biopsy can be dispensed with when the tomography reveals interstitial opacities in an appropriate clinical and epidemiological context ${ }^{(6,7)}$.

When there is no clinical suspicion of GD, a tomographic finding of the crazy-paving pattern makes the radiologic diagnosis difficult ${ }^{(9)}$. In such cases, the main differential diagnoses are alveolar proteinosis, pulmonary hemorrhage, pulmonary vasculitis, diffuse alveolar damage (acute respiratory distress syndrome), pulmonary edema, bronchioloalveolar carcinoma, Niemann-Pick disease, and radiation pneumonitis, as well as Pneumocystis, viral, lipoid, mycobacterial, interstitial, and eosinophilic pneumonia.

\section{REFERENCES}

1. Beutler E. Gaucher's disease. N Engl J Med. 1991;325:1354-60.
2. Pastores GM, Hughes DA. Gaucher disease. 2000 Jul 27 [Updated 2015 Feb 26]. In: Adam MP, Ardinger HH, Pagon RA, et al. GeneReviews ${ }^{(}$ [Internet]. Seattle (WA): University of Washington, Seattle; 1993-2017. [cited 2017 Oct 30]. Available from: www.ncbi.nlm.nih.gov/books/ NBK1269/.

3. Mendonça VF, Paula MTM, Fernandes C, et al. Manifestações esqueléticas da doença de Gaucher. Radiol Bras. 2001;34:151-4.

4. Wolson AH. Pulmonary findings in Gaucher's disease. Am J Roentgenol Radium Ther Nucl Med. 1975;123:712-5.

5. Kerem E, Elstein D, Abrahamov A, et al. Pulmonary function abnormalities in type I Gaucher disease. Eur Respir J. 1996;9:340-5.

6. Aydin K, Karabulut N, Demirkazik F, et al. Pulmonary involvement in adult Gaucher's disease: high resolution CT appearance. Br J Radiol. 1997;70:93-5.

7. Amir G, Ron N. Pulmonary pathology in Gaucher's disease. Hum Pathol. 1999;30:666-70.

8. Yassa NA, Wilcox AG. High-resolution CT pulmonary findings in adults with Gaucher's disease. Clin Imaging. 1998;22:339-42.

9. Müller CIS, D’Ippolito G, Rocha AJ. Tórax. Série Colégio Brasileiro de Radiologia e Diagnóstico por Imagem: Tórax. 1 a edição. Rio de Janeiro, RJ: Elsevier; 2010.

Lucas de Pádua Gomes de Farias ${ }^{1}$, Igor Gomes Padilha ${ }^{1}$, Carla Jotta Justo dos Santos ${ }^{2}$, Carol Pontes de Miranda Maranhão ${ }^{2}$, Christiana Maia Nobre Rocha de Miranda ${ }^{2}$

1. Universidade Federal de Alagoas (UFAL), Maceió, AL, Brazil. 2. Clínica de Medicina Nuclear e Radiologia de Maceió (MedRadius), Maceió, AL, Brazil. Mailing address: Dra. Christiana Maia Nobre Rocha de Miranda. Clínica de Medicina Nuclear e Radiologia de Maceió (MedRadius). Rua Hugo Corrêa Paes, 104, Farol. Maceió, AL, Brazil, 57050-730. E-mail: maia.christiana@ gmail.com.

http://dx.doi.org/10.1590/0100-3984.2016.0081

\section{Retroperitoneal Ewing's sarcoma/embryonal tumor: a rare differential diagnosis of back pain}

\section{Dear Editor,}

A previous healthy 17 -year-old female was referred to a rheumatology clinic due to a 6-month history of lower back pain. Her pain worsened at night and did not radiate. During that 6 -month period, she had lost weight $(5 \mathrm{~kg})$. An initial evaluation produced normal cardiovascular and abdominal findings. She had pain on lumbar spine palpation and pain when her sacroiliac joints were examined (Patrick's test). Laboratory tests showed normal blood smear results and normal levels of inflammatory markers. While waiting for a magnetic resonance imaging (MRI) scan of her sacroiliac joint, she returned with significant worsening of her pain and weakness in her right leg. Examination showed grade 3 muscle strength and an absence of the ipsilateral patellar reflex. MRI revealed a right paravertebral mass, with intradural and foraminal components, showing a signal that was, in comparison with the muscle signal, predominantly isointense (with a hyperintense component indicating hemorrhage) on T1-weighted images and isointense (with a hyperintense necrotic component) on T2-weighted images (Figure 1). Ultrasound-guided biopsy revealed an undifferentiated small round-cell morphology. Immunohistochemistry staining suggested a member of the Ewing's sarcoma/embryonal tumor (ES/ET) family (Figure 2). The patient was submitted to chemotherapy, which did not elicit an adequate response.

ES/ETs belong to a rare group of malignant neoplasms with small round-cell morphology. Although these tumors arise from a common precursor cell, each entity represents a different expression of the same neoplasm, characterized by distinct cellular differentiation or anatomic location ${ }^{(1)}$. 